\title{
A paisagem e os potenciais atrativos turísticos da bacia hidrográfica do altíssimo rio Tibagi (Paraná, Brasil)
}

\section{Landscape and its potencial tourism attractions in the hydrographic basin of the most upper Tibagi river (Paraná, Brazil)}

\author{
Tiago Damas Martins \\ Miguel Bahl \\ Universidade Federal do Paraná
}

\begin{abstract}
Resumo: $\mathrm{O}$ trabalho objetiva identificar os potenciais atrativos turísticos, a partir da caracterização da paisagem regional na área onde se localizam as nascentes do rio Tibagi, no estado do Paraná (Brasil). Inicialmente foi feita a revisão bibliográfica para caracterizar as peculiaridades dos Campos Gerais do Paraná. Posteriormente foram realizadas atividades de campo num itinerário que percorre a área de estudo, com a intenção de inventariar os elementos naturais e culturais nele contidos. Nas atividades de campo utilizou-se carta topográfica escala 1:50.000; um GPS para referenciamento do itinerário e documentação fotográfica. Tais procedimentos evidenciam como resultado o potencial paisagístico da área para uso turístico e a existência de um patrimônio natural e cultural de grande expressividade, respaldando a ideia da proposição de desenvolver atividades turísticas específicas ou associá-las como incremento aos projetos já existentes.
\end{abstract}

Palavras-chave: Campos Gerais. Rio Tibagi. Potencialidade turística. Atrativos turísticos.

\begin{abstract}
The research is aimed at identifying the potential tourist attractions, based on a description of the regional landscape where the sources of the Tibagi River in Paraná state (Brazil) are located. After a bibliographical review had been elaborated in order to identify the specific characteristics of the regional landscape that is known as Campos Gerais of Paraná, field work has been carried out along an itinerary that crosses the analyzed area, with the intention to inventory the natural and cultural elements of the area. Those activities have been performed by using a topographical map on the scale of 1:50.000 and a GPS to mark specific locations along the itinerary, in combination with photographic recording. Thus, the touristic landscape potential of the area and the existence of natural and cultural heritages can be evidenced as being of great relevance, in order to propose specific tourism oriented measures, or to integrate such measures into currently existing projects.
\end{abstract}

Keywords: Campos Gerais. Tibagi river. Tourism potential. Tourist attractions. 


\section{INTRODUÇÃO}

A elaboração deste trabalho objetivou identificar potenciais atrativos turísticos através da caracterização da paisagem da área onde se localizam as nascentes do rio Tibagi, junto à escarpa devoniana, região natural conhecida como Campos Gerais do estado do Paraná (Brasil). O estudo permitiu revelar a potencialidade paisagística da área para uso turístico, evidenciada pela singularidade dos elementos naturais e culturais que a compõem e que podem ser utilizados como atrativos. Tais elementos foram inventariados durante percurso percorrido na área e que culminou no traçado de um itinerário.

Historicamente o termo paisagem integra o escopo teórico e científico da Geografia, "tendo sido introduzido como termo científico-geográfico no início do século XIX por Alexander Von Humboldt". (KICHE et al., 2006, p. 2).

Segundo Monteiro (2000, p. 39), a paisagem pode ser definida como:

[...] uma entidade espacial delimitada segundo um nível de resolução do pesquisador, a partir dos objetivos centrais da análise, de qualquer modo sempre resultado de integração dinâmica e, portanto, instável dos elementos de suporte e cobertura (físicos, biológicos e antrópicos), expressa em partes delimitáveis infinitamente, mas individualizadas através das relações entre elas que organizam um todo complexo (sistema) verdadeiro conjunto solidário em perpétua evolução.

Para Ferretti (2002, p. 19), a paisagem assume destacável importância na oferta turística, apontando que "a paisagem e o turismo são realidades que se interrelacionam".

Dessa forma, adotou-se neste trabalho uma definição de paisagem relacionada ao turismo, em que, de acordo com Pellegrini Filho (2000, p. 190), ela é a "área que a visão humana pode alcançar, incluindo elementos físicos (montes e montanhas, rios, lagoas, praias etc.), biológicos (flora e fauna) e o próprio ser humano e seus artefatos, em interação". Tal definição está alinhada aos elementos descritos ao longo do trabalho, servindo como suporte à atividade turística para a sua melhor contemplação e usufruto.

A paisagem dos Campos Gerais conserva elementos naturais de um tempo geológico pretérito, revelando-se, portanto, como uma paleopaisagem, sendo essa sua característica mais peculiar.

Tal composição natural despertou ao longo do tempo a atenção de viajantes e pesquisadores, como o antropólogo francês Lévi-Strauss (1996, p. 143), que, encantado com o quadro natural da região, cita: "possam vossos passos vacilar à entrada das pradarias desabitadas e da grande floresta úmida de coníferas [...]". Ainda, anterior a ele, o engenheiro inglês Bigg-Wither, em sua passagem pela região no século XIX, comenta impressionado que "a sua imensidão nos dava a idéia de ilimitado [...] Foi, pelo menos essa, a sensação que experimentei [...] ao entrarmos nos Campos Gerais". (BIGG-WITHER, 1974, p. 67).

Diante de tais depoimentos a possibilidade de se trabalhar com atividades de turismo nessa área também foi um dos aspectos vislumbrados, pois: "traduzindo o aspecto fisiográfico da paisagem, através da topografia diferenciada e de configuração física por vezes marcante, o relevo torna-se o grande diferencial turístico de um país, região ou município". (BAHL, 2004, p. 36). Além disso, na mesma obra encontra-se que "as formações ímpares promovem forte atratividade" e nela são citados, dentre alguns exemplos, as formações areníticas de Vila Velha no Paraná, o Grand Canyon nos Estados Unidos e o de Itaimbezinho no Rio Grande do Sul. 
$\mathrm{Na}$ busca de se atingir o objetivo desta investigação, a pesquisa foi realizada a partir da revisão bibliográfica pertinente ao entendimento das características da paisagem natural dos Campos Gerais. Foram realizadas, também, atividades de campo em itinerário percorrido para delimitação de área de estudo mais restrita e para inventariar os elementos naturais e culturais nela contidos. Posteriormente foram identificados os projetos turísticos oficiais desenvolvidos ou em desenvolvimento naquela unidade de paisagem, com a intenção de verificar a pertinência de nova inserção de uso turístico. Como propostas vinculadas a este trabalho, em que se levou a cabo a identificação de potenciais atrativos naturais e culturais na área de estudo delimitada, é importante mencionar que foram utilizados dados obtidos a partir de um itinerário também percorrido nas atividades de campo de uma pesquisa anterior (MARTINS, 2008), facilitando, assim, a realização das atividades de observação in loco. A partir de tais procedimentos, também ficou evidenciado o potencial paisagístico de grande apelo turístico da área onde ocorre o sistema de drenagem formado pelas nascentes do rio Tibagi, classificado como Bacia Hidrográfica do Altíssimo Rio Tibagi - BHART (Figura 1).

\section{Localização da Bacia Hidrográfica do Altíssimo Tibagi - PR}

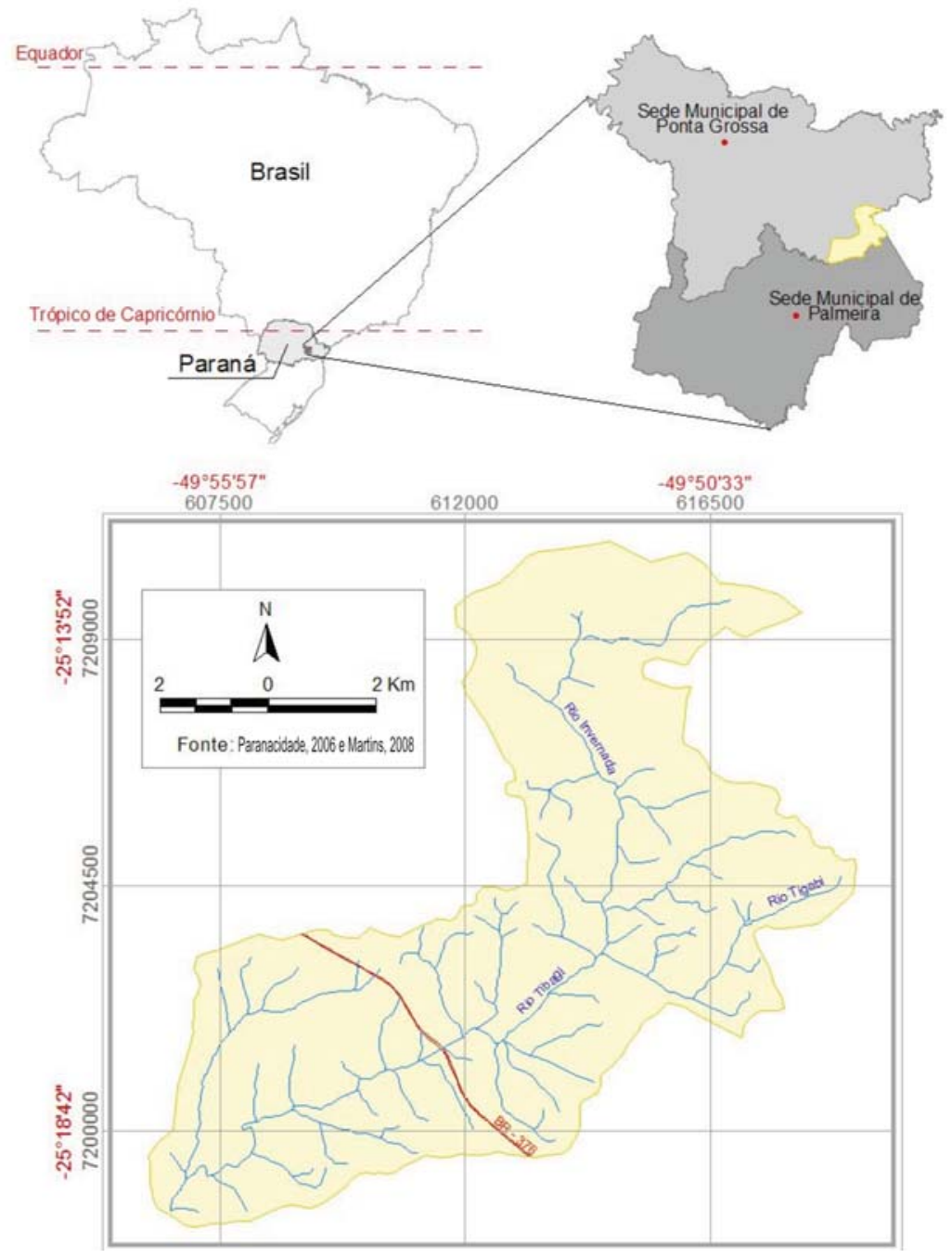

Figura 1 - Localização da área de estudo no Brasil - BHART

Fonte: PARANACIDADE, 2006 e MARTINS, 2008. 
A pesquisa comprovou existir potencial para uso turístico da área em função da sua diversidade natural e de seu conteúdo histórico-cultural - ambos bastante expressivos e dotados de grande potencialidade para o desenvolvimento de atividades de cunho turístico não predatório - e pela própria beleza cênica da paisagem onde estão inseridos.

Julga-se pertinente esclarecer que o foco principal de tal abordagem ateve-se ao itinerário traçado, prevendo-se que numa fase posterior possam ser aprofundados estudos sobre o espaço de entorno num âmbito regional, pois as atividades deverão estar integradas a esse conjunto mais amplo.

\section{MATERIAL E PROCEDIMENTOS TÉCNICOS}

Para a efetivação das atividades de campo utilizou-se a carta topográfica Folha QueroQuero (MI 2841-3), do Instituto Brasileiro de Geografia e Estatística - IBGE, em escala 1:50.000, com equidistância entre as curvas de nível de 20 m; um GPS (Global Position

Figura 2 - Mapa do itinerário percorrido nas atividades de campo Fonte: PARANACIDADE, 2006 e MARTINS, 2008.
System) modelo Garmin Etrex para o referenciamento das coordenadas dos pontos do roteiro e traçado do itinerário; além desses, foi realizada uma documentação fotográfica.

No desenvolvimento do traçado do itinerário (Figura 2) utilizaram-se dados das curvas de nível, hidrografia e estradas de rodagem da carta topográfica mencionada, digitalizados pelo PARANACIDADE (2006). Esses dados foram processados no software ArcView GIS 3.2.

O itinerário foi traçado seguindo o curso do rio Tibagi na área de estudo. Com início no viaduto da BR 376 sobre o rio, o trajeto prossegue junto à borda do cânion formado à jusante da confluência do rio Tibagi com o arroio Invernada; em seguida, continua até o local apontado como nascente do rio, no Sítio das Almas. Então, estende-se por $12 \mathrm{~km}$ entre os municípios de Palmeira e Ponta Grossa, recortando propriedades rurais privadas.

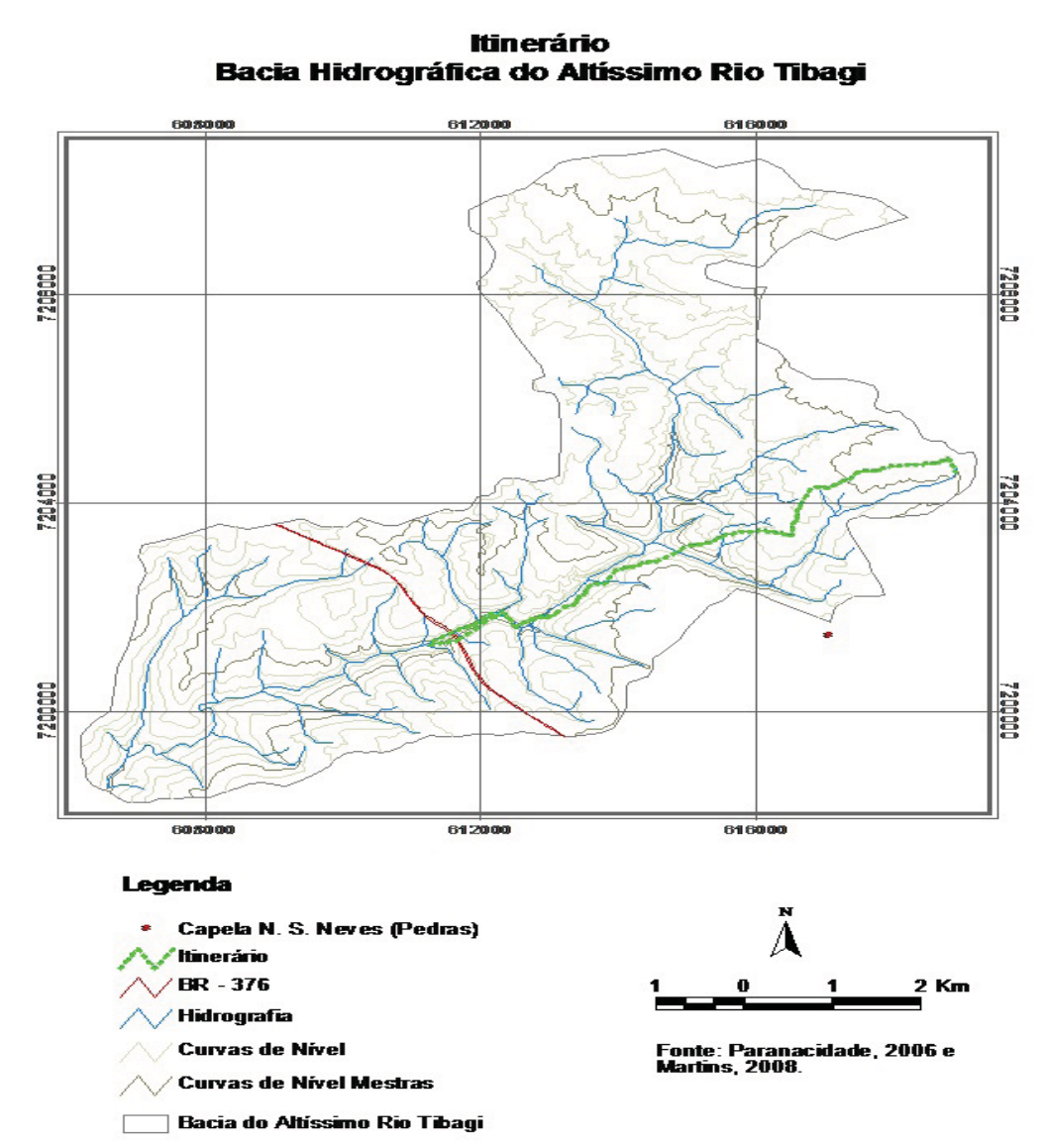




\section{OS CAMPOS GERAIS DO PARANÁ}

A expressão "Campos Gerais do Paraná" foi consagrada por Maack (1948), que descreveu a região como uma zona fitogeográfica natural, com campos limpos e matas de galerias ou capões isolados de Floresta Ombrófila Mista, onde aparece o pinheiro araucária.

Essa paisagem se originou em um tempo geológico pretérito e sob "condições muito secas e bem mais frias" (AB'SABER, 2003, p. 103) do que as atuais condições climáticas. Tais características promoveram o surgimento de "amplas e descobertas áreas de gramíneas [...]" (MAACK, 1981, p. 257). Revela-se, portanto, uma paleopaisagem dominada por uma vegetação reliquiar de uma época geológica mais seca e fria do Quaternário. (MAACK, 1948 e 1981).

Para Ab'Saber (2003, p. 105), o planalto regional onde se situam os Campos Gerais caracteriza-se por um "desdobrar de chapadões ondulados marcados por mosaicos de campos de cimeira e pequenos bosques de araucária". Ali, destacam-se "alguns morros testemunhos, de rochas ligeiramente mais resistentes e fortemente fissuradas, uma das topografias ruiniformes mais extraordinárias do país".

Entremeadas nessa vegetação de gramíneas baixas, surgem "ilhas" de matas conhecidas como capões, além da mata de galeria, identificadas por Maack (1981) como Floresta Ombrófila Mista. Ainda para esse autor (Ibidem, p. 258) "os capões se desenvolveram em depressões mais úmidas ao redor das nascentes, conquistando lentamente os declives sob condições climáticas favoráveis", expandindo-se e unindo-se a outros capões para constituir um complexo agrupamento florestal.

Essa unidade de paisagem se estende por 19.060 km² (Ibidem) na porção centrooriental do Segundo Planalto Paranaense, ou Planalto de Ponta Grossa. Unidade fisiográfica limitada a Leste pela escarpa erosiva, nomeada de escarpa devoniana e a Oeste pela escarpa da Serra Geral, tendo sua inclinação geral para Oeste, Sudoeste e Noroeste. (Ibidem).

O relevo regional é contrastante, pois nas proximidades da cuesta erosiva da escarpa devoniana, grandes amplitudes se desenvolvem, "com freqüentes encostas abruptas, verticalizadas, com canyons e trechos de rios encaixados". (UEPG, 2004, p. 43). Seguindo no sentido Oeste, afastando-se da escarpa, "passa a predominar paisagem de topografia suavemente ondulada de configuração muito uniforme, formada por conjuntos de colinas, com declives suaves e amplitude inferior a 50 metros". (Ibidem).

Inúmeras outras feições são características dos Campos Gerais, dentre elas, feições ruiniformes, identificadas pelos expressivos processos erosivos em rochas superficiais, como os arenitos do Parque Estadual de Ponta Grossa, morros testemunhos e as conhecidas Furnas, depressões cilíndricas e abertas no topo, desenvolvidas da superfície para o interior da estrutura da rocha. Além desses a própria escarpa devoniana, que favorece o surgimento de inúmeros cânions, sendo o de maior destaque o cânion do Guartelá, formado pelo rio Iapó.

O sistema climático atuante na região é de tipo subtropical úmido, com verões moderadamente quentes e média pluviométrica de $1.550 \mathrm{~mm}$. A média de temperatura é de $18^{\circ} \mathrm{C}$ - com média máxima de $24^{\circ} \mathrm{C}$ e média mínima de $13^{\circ} \mathrm{C}$ (STIPP, 2000) - e destaque para a "atuação conjugada dos Sistemas Atmosféricos Intertropicais e Polares". (Ibidem, p. 36). Além disso, a UEPG (2004, p. 46) aponta que "na escarpa devoniana, chove de 100 a $300 \mathrm{~mm}$ anuais a mais do que no Primeiro Planalto que o antecede". 
Tais condições evidenciam padrões climáticos distintos daqueles que, em um passado geológico distante, elaboraram essa paisagem com seu quadro fitogeográfico tão peculiar. Esse fator, juntamente com suas características geomorfológicas e hidrográficas, vem a evidenciar o destaque dos Campos Gerais do Paraná como uma unidade de paisagem ímpar e de ampla potencialidade para o desenvolvimento de atividades turísticas baseadas em ecoturismo, educação ambiental, caminhadas, práticas esportivas e de cunho informativo.

\section{POTENCIALIDADE TURÍSTICA REGIONAL}

Historicamente, o desenvolvimento da ocupação e colonização por povos não nativos nos Campos Gerais do Paraná se deu em função do Caminho das Tropas (NADALIN, 200, p. 49). Ainda, segundo o mesmo autor, tal caminho ligava Viamão, no atual estado do Rio Grande do Sul "aos Campos Gerais no Paraná; na continuidade, fazia elo com as feiras de São Paulo, principalmente Sorocaba". Também menciona que se caracterizava como uma rota comercial para o transporte de animais - especialmente muares - criados na região de Viamão, para os mercados de São Paulo.

Com o intuito de promover turisticamente os municípios que têm relação histórica com o Caminho das Tropas, foi desenvolvido em 1997 o projeto intitulado Rota dos Tropeiros, sendo que sua implantação ocorreu em 2003. (PIEKARZ; LICCARDO, 2007). Sua proposta “visa a composição de uma metodologia para o desenvolvimento sustentável da região, com base no tema Tropeirismo". (SANTOS; MOLIN, 2008, p. 64).

Piekarz e Liccardo (2007) apontam que a Rota dos Tropeiros é um roteiro turístico que envolve 17 municípios paranaenses: Rio Negro, Campo do Tenente, Lapa, Balsa Nova, Porto Amazonas, Campo Largo, Palmeira, Ponta Grossa, Carambeí, Castro, Tibagi, Telêmaco Borba, Piraí do Sul, Ventania, Arapoti, Jaguariaíva e Sengés. Também mencionam que tal projeto é operado pela agência homônima criada em 2007.

Os mesmos autores alegam que outro projeto se utiliza da temática do tropeirismo, mas com foco nos atrativos naturais da região, foi desenvolvido em 2005 pela Minerais do Paraná - MINEROPAR, denominado Levantamento de Sítios Geológicos e Paleontológicos ao longo da Rota dos Tropeiros. Eles discorrem que o objetivo da proposta é o de agregar ao atrativo Rota dos Tropeiros informações sobre os sítios geológicos que ocorrem ao longo do caminho.

O projeto Rota dos Tropeiros e seu incremento fazem uso das características histórico-culturais e naturais da região dos Campos Gerais como produto turístico e, como aponta Zuccherelli (2008, p. 57), "supõe a retificação de uma identidade regional, identidade esta construída em oposição a outros tipos de turismo".

O patrimônio natural da região também é alvo de atos oficiais que promovam ações de preservação e conservação dos seus sítios naturais. A região contava em 2004 com 28 Unidades de Conservação (UEPG, 2004), divididas em quatro parques estaduais, uma Área de Proteção Ambiental (APA) e 23 Reservas Particulares do Patrimônio Natural (RPPNs). Além desses, o Governo Federal, através do Instituto Brasileiro do Meio Ambiente - IBAMA, e dos Recursos Naturais Renováveis cria, em 2006, o Parque Nacional dos Campos Gerais, objetivando "a proteção de remanescentes do Mioma Mata Atlântica, composto por Floresta Ombrófila Mista e a estepe associada". (ALMEIDA; MORO, 2007, p. 117). 
Tais iniciativas evidenciam o potencial paisagístico regional, resultante da intrincada relação entre os elementos oriundos do seu patrimônio histórico-cultural e os da natureza que a compõem, pois "em toda sua extensão, apresentam atrativos naturais belíssimos, possuindo um grande potencial para a prática do Ecoturismo". (UEPG, 2004, p. 207).

\section{BACIA HIDROGRÁFICA DO ALTÍSSIMO RIO TIBAGI - BHART}

No reverso da escarpa devoniana, entre os municípios de Palmeira e Ponta Grossa, surge um planalto dominado por campos nativos e capões de mata de araucária, onde se localizam as cabeceiras de drenagem do rio Tibagi. (MARTINS, 2008). Esse rio configura-se como um importante sistema hídrico do estado do Paraná, por abranger uma bacia hidrográfica de 25.239 $\mathrm{km}^{2}$. (MAACK, 1981). Percorre aproximadamente $550 \mathrm{~km}$ até sua foz na margem esquerda do rio Paranapanema. (Ibidem). A bacia hidrográfica formada por esse rio se estende pelos três planaltos paranaenses, sendo sua maior abrangência no Segundo Planalto. (STIPP, 2000).

Este estudo se limitou a investigar a área formada pelo sistema de drenagem constituído na zona natural mais elevada de toda a bacia hidrográfica do rio Tibagi, identificado como Bacia Hidrográfica do Altíssimo Rio Tibagi - BHART. (MARTINS, 2008). Esse sistema hidrográfico, com elevações superiores a $1.100 \mathrm{~m}$ de altitude, é limitado pela confluência do rio do Salto com o rio Tibagi.

Sendo assim, a área de abrangência da BHART é de $72,93 \mathrm{~km}^{2}$ e perímetro de 53,02 $\mathrm{km}$, localizando-se entre os municípios de Palmeira e Ponta Grossa. Seus limites geográficos são definidos no Quadro 1 a seguir:

\begin{tabular}{|c|c|}
\hline LIMITES & COORDENADAS \\
\hline Norte & $-25^{\circ} 12^{\prime} 55.9^{\prime \prime}$ e $-49^{\circ} 51^{\prime} 45.4^{\prime \prime}$ \\
\hline Sul & $-25^{\circ} 19^{\prime} 45.7^{\prime \prime}$ e $-49^{\circ} 56^{\prime} 17.5^{\prime \prime}$ \\
\hline Leste & $-25^{\circ} 16^{\prime} 09.8^{\prime \prime}$ e $-49^{\circ} 49^{\prime} 00.9^{\prime \prime}$ \\
\hline Oeste & $-25^{\circ} 19^{\prime} 02.3^{\prime \prime}$ e $-49^{\circ} 56^{\prime} 41.9^{\prime \prime}$ \\
\hline
\end{tabular}

Quadro 1: Limites geográficos da BHART. Fonte: MARTINS, 2008.

A área em questão abriga importantes remanescentes da vegetação de campos nativos, assim como aponta Stipp (2000), citando que as condições ambientais daquela área, identificada em seu trabalho como Alto Tibagi III (Região de Porto Amazonas), "podem ser consideradas de degradação média a baixa, fato explicado pela representatividade de matas e pastagens naturais [...]". (Ibidem, p. 196). Essa condição reflete a qualidade ambiental presente, sendo esse um elemento essencial no desenvolvimento de atividades turísticas. (BRAZ; CALVENTE, 2003).

\section{POTENCIAIS ATRATIVOS TURÍSTICOS DA BHART}

Ignarra (2001, p. 48) considera complexa e subjetiva a definição de um atrativo turístico. Não obstante, também aponta que um atrativo turístico "possui, via de regra, maior valor quanto mais acentuado for seu caráter individual".

Em Bahl (2004, p. 67) encontra-se que "normalmente, os elementos naturais possuem uma conotação muito forte como motivadores para visitação, despertando grande interesse nas pessoas". Porém, ao mesmo tempo alerta que "[...] deve-se salientar a importância em estar-se atento aos fluxos quantitativos aos atrativos naturais, evitando-se a degradação e ocupação desordenadas" (Ibidem).

No entanto, para que um elemento natural passe a atuar como atrativo turístico, 
ele deve contar com acesso e instalações que facilitem sua visitação. Além disso, deve estar situado em locais em que as visitas turísticas sejam permitidas dentro das normas ambientais vigentes.

A partir de tais considerações, tornase pertinente esclarecer que os elementos naturais investigados nesta pesquisa ainda não possuem tais facilidades para visitação, tendo, portanto, um caráter de potenciais atrativos turísticos.

Dessa forma, discorre-se sobre potenciais atrativos turísticos da área, que são descritos a seguir:

\subsection{Nascente do rio Tibagi}

Em sua passagem pelos Campos Gerais na segunda metade do século XIX, vindo de Curitiba a caminho de Ponta Grossa, o inglês Bigg-Whiter (1974, p. 86) assinala que a nascente do rio Tibagi ocorre "no meio daquelas regiões altas de campinas, recebendo [...] pequenos tributos de alguns ribeiros e regatos e ignorando assim o grande destino que o esperava".

Já no século seguinte, após estudo detalhado do rio, Maack (1981) aponta que as nascentes do rio Tibagi estão localizadas nos Campos Gerais e são formadas no reverso da escarpa devoniana. $\mathrm{O}$ autor complementa afirmando que o "curso superior do rio Tibagi acompanha uma fenda estrutural vertical e retilínea do arenito Furnas [...] após a embocadura do arroio da Invernada" (Ibidem, p. 321), sendo que a jusante recebe a confluência do rio do Salto.

Dessa forma, considera-se que o canal que recebe a afluência do arroio Invernada é a nascente do rio Tibagi. De acordo com Martins (2008), o "olho d'água" (Figura 3) formador desse canal, está localizado no Sítio das Almas, nas coordenadas $25^{\circ} 16^{\prime} 14.8^{\prime \prime}$ Sul e $49^{\circ} 49^{\prime} 10.3^{\prime \prime}$ Oeste, entre os municípios de Ponta Grossa e Palmeira, sendo a área propriedade da família Lopez (Figura 4).

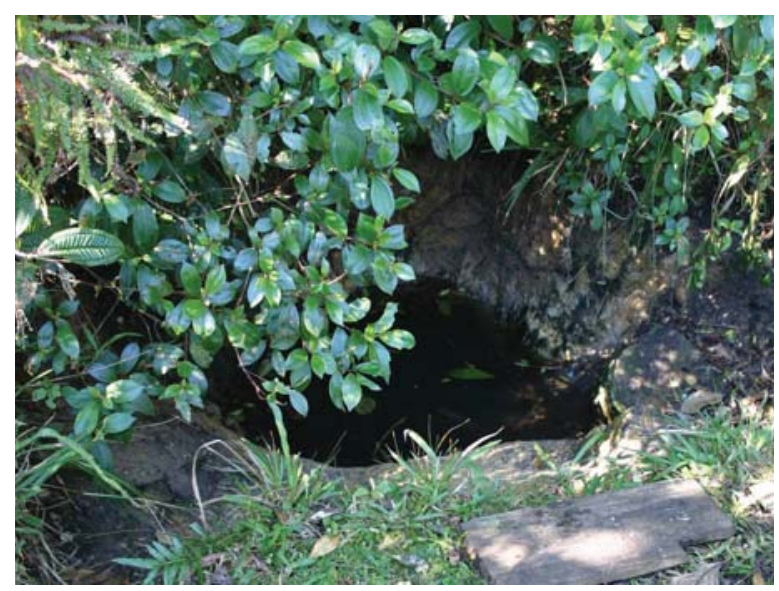

Figura 3 - Olho d'água formador do rio Tibagi Foto: MARTINS, 2006

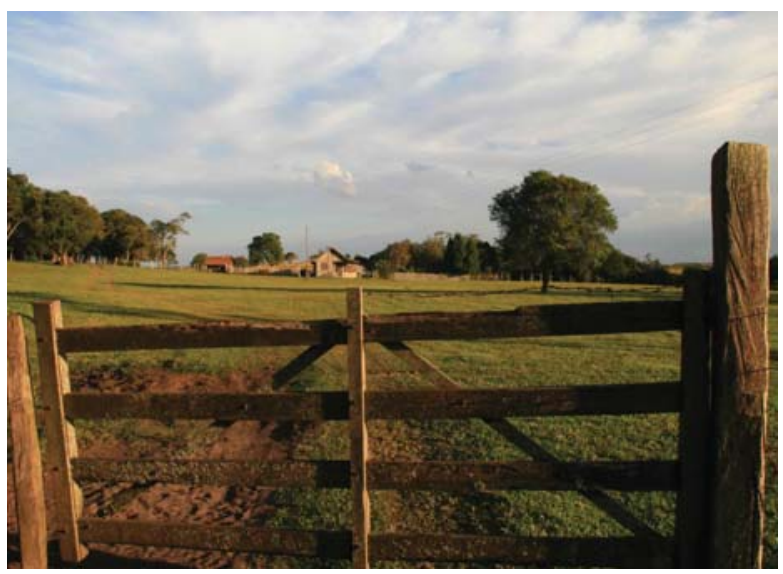

Figura 4 - Sítio das Almas Foto: MARTINS, 2009

\subsection{Campos nativos e capões de mata}

A própria configuração paisagística da área, que está inserida dentro da região natural dos Campos Gerais, conserva em seu quadro fitogeográfico remanescentes de campos nativos e capões de mata (Figura 5), formados em um período geológico pretérito e com degradação baixa e média, conforme mencionado anteriormente. 


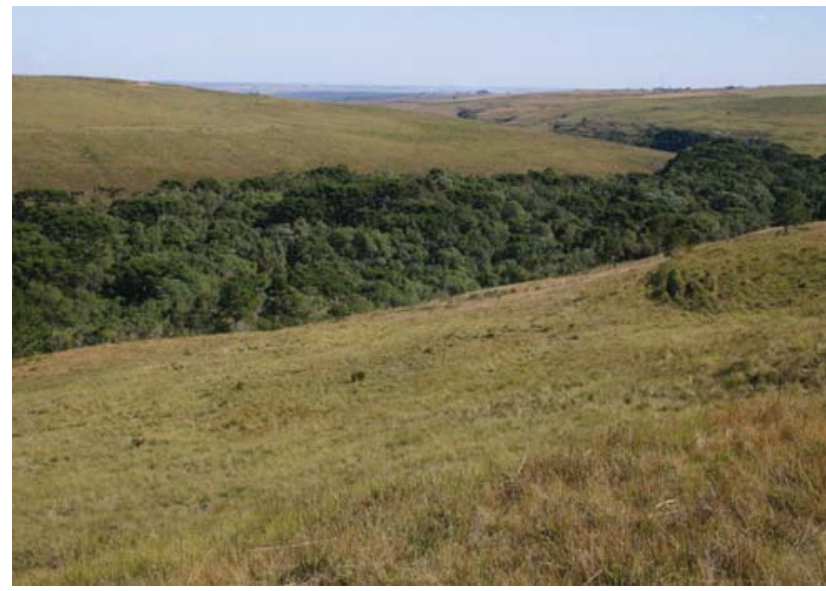

Figura 5 - Domínio de campos nativos entremeado por capões de mata

Foto: MARTINS, 2006

\subsection{Sistema hidrográfico e relevo}

Uma atração à parte está no próprio sistema hidrográfico formado pela BHART, que apresenta dois tipos de leito: lajeado (Figura 6), expondo a estrutura geológica sem aprofundamento acentuado, e os cânions (Figura 7), com expressiva dissecação vertical da estrutura geológica, em função do aproveitamento do canal do sistema de falhas e fraturas na estrutura geológica regional. (MARTINS, 2008).

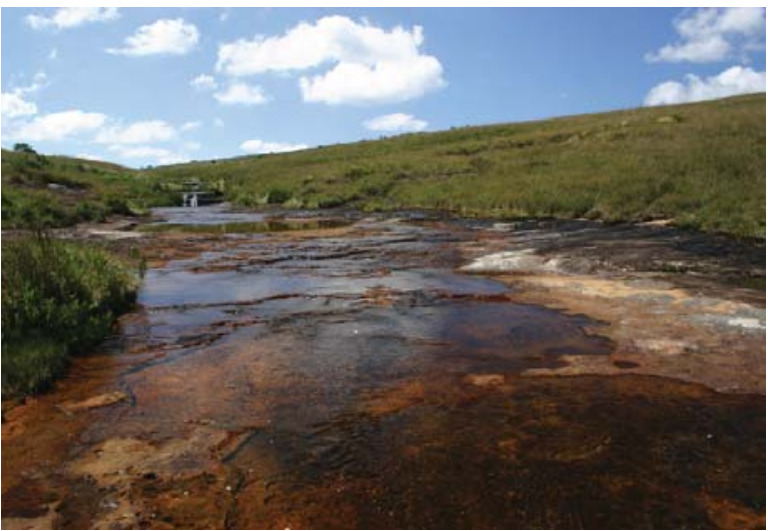

Figura 6 - Leito tipo lajeado - rio Tibagi Foto: MARTINS, 2007

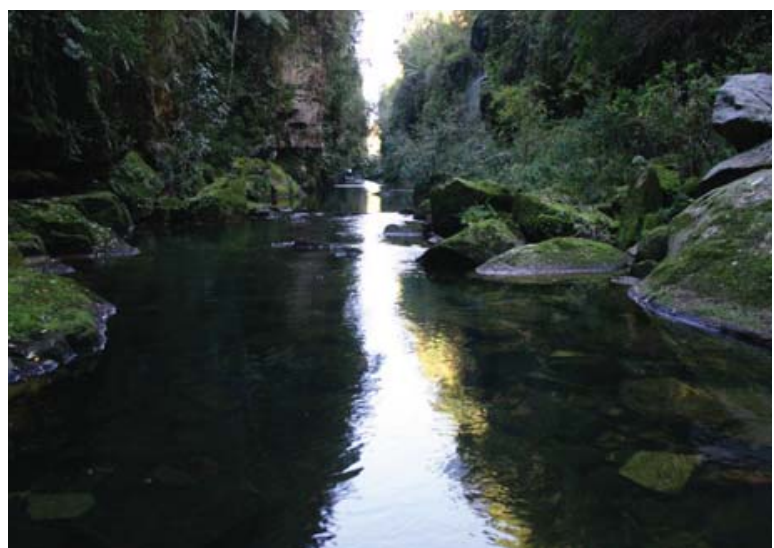

Figura 7 - Sistema de falhas e fraturas favorece o surgimento de cânions - rio Tibagi Foto: MARTINS, 2007

\subsection{Feições ruiniformes}

Além desses, formam-se na região superfícies rochosas verticalmente erodidas desenvolvidas no Arenito Furnas (Figura 8), representando testemunhos de feições geológicas passadas. (MARTINS, 2008).

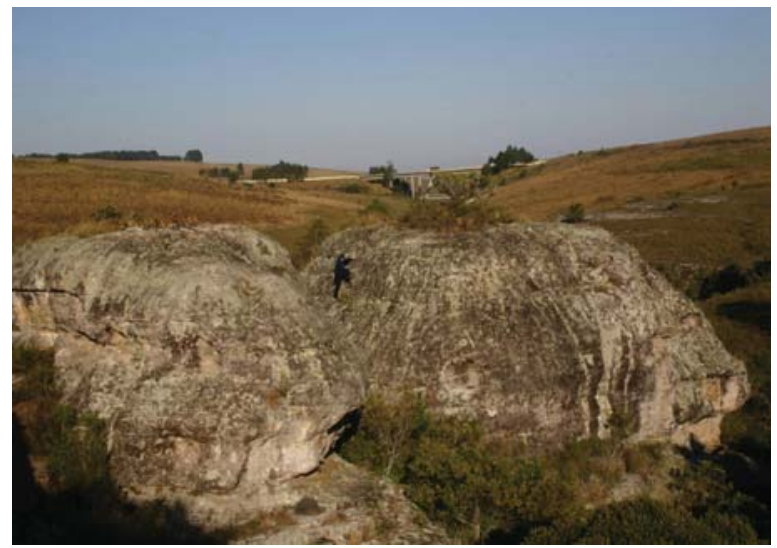

Figura 8 - Feições ruiniformes Foto: MARTINS, 2006

Ressalta-se ainda que, adjacentes à área de estudo, também foram identificados outros potenciais atrativos turísticos, conforme descritos a seguir: 


\subsection{Escarpa devoniana e serra de Itaiacoca}

Compondo um cenário dos mais expressivos, destaca-se a escarpa devoniana (Figura 9), um degrau natural no relevo, que separa a zona de floresta dos campos nativos e que circunda todo o setor norte, nordeste e leste da BHART. Ainda compondo a porção norte tem-se a serra de Itaiacoca (Figura 10), formada por um conjunto de morros testemunhos, que resguardam uma vegetação campestre em seu topo, sendo que a Floresta Ombrófila Mista cobre suas bases.

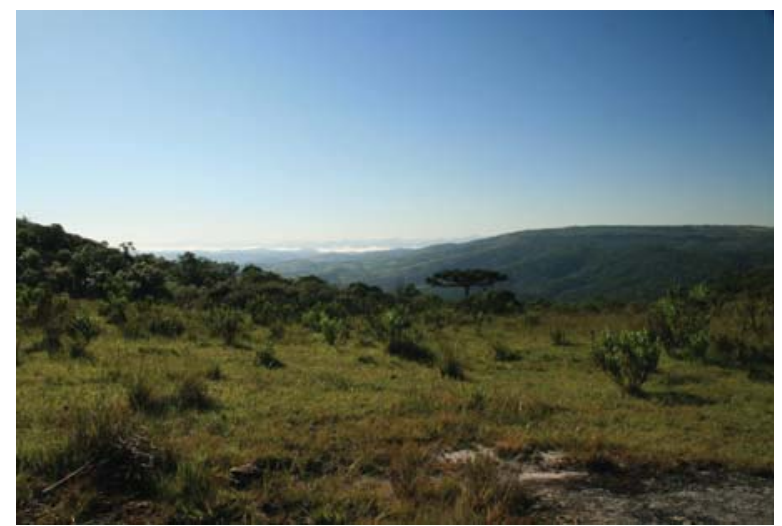

Figura 9 - Escarpa devonina Foto: MARTINS, 2009

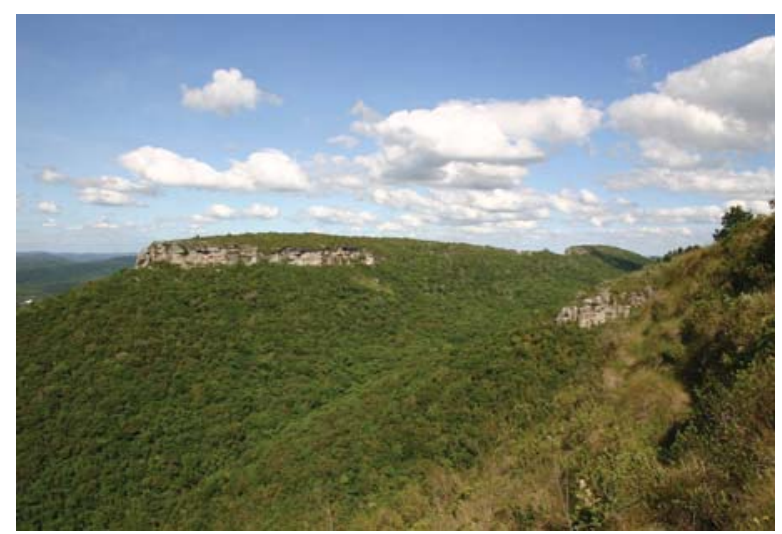

Figura 10 - Serra de Itaiacoca Foto: MARTINS, 2005

\subsection{Capela Nossa Senhora das Pedras}

Ao leste, encontramos ainda a Capela Nossa Senhora das Pedras, também conhecida como Capela Nossa Senhora das Neves (Figura 11), que tem a sua origem e edificação relacionada a lendas populares. (LOPES, 2000).

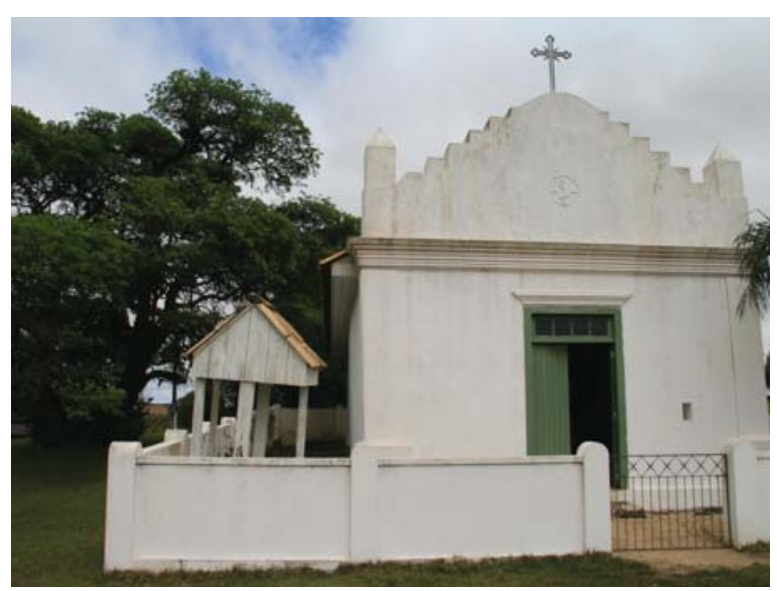

Figura 11 - Capela Nossa Senhora das Pedras Foto: MARTINS, 2009

Os elementos naturais e culturais aqui destacados compõem a região dos Campos Gerais do Paraná e expressam a potencialidade dos mesmos para o desenvolvimento de atividades de turismo. Tais elementos podem ser utilizados como atrativos por diferentes segmentos do turismo e como estratégia econômica para atrair visitantes que se relacionem às atividades ecológicas, de aventura, científicas e históricoculturais.

\section{CONSIDERAÇÕES FINAIS}

A paisagem formada pelos Campos Gerais do Paraná destaca-se por suas peculiares características, distinguindo-se como uma "paisagem do passado". Sua colonização também evidencia particularidades representadas através do patrimônio histórico-cultural. Por sua vez, parte desse patrimônio já está sendo utilizado para fins turísticos, tendo como destaque 
o projeto Rota dos Tropeiros, de vínculo cultural, e outro, de características mais naturais, a partir dos Sítios Geológicos e Paleontológicos da MINEROPAR.

Este trabalho possibilitou identificar, a partir do itinerário percorrido, outros potenciais atrativos turísticos na área das nascentes do rio Tibagi e cercanias; sendo que os mesmos ainda não são utilizados dentro das propostas de projetos turísticos para a região dos Campos Gerais.

Todos esses potenciais atrativos dão destaque para a área, no que concerne ao desenvolvimento de um novo projeto turístico que as coloque em uso, sendo que suas características naturais podem favorecer a prática de atividades de turismo esportivo, tais como: rapel na descida de obstáculos; canionismo ao percorrer rios, gargantas e cânions; caminhadas para contemplação da paisagem, com fundamentos ecológicos, científicos ou ligadas ao turismo geológico. Sendo possível também associá-los como um incremento aos projetos já existentes e apontados neste trabalho (Rota dos Tropeiros e Sítios Geológicos e Paleontológicos).

Tais propostas não estão atreladas a investir em instalações ou construções que interfiram na paisagem, pois os atrativos naturais, conforme alerta Bahl (2004, p. 35): "podem necessitar de uma estrutura adequada para a visitação, utilização e aproveitamento (estradas, trilhas, passarelas, pontes, elevadores, teleféricos e outros)". Além disso, "estão sujeitos à ingerência humana sob diversas formas: acúmulo de lixo, [...] visitação massiva, etc.". (Ibidem).

O vínculo principal está associado à perspectiva de se trabalhar com atividades de menor impacto possível e de basicamente propiciar aos usuários percorrer, sentir, visualizar e compreender o estado atual e de transformação física de uma das áreas naturais de maior expressividade visual e paisagística do Brasil, pois os atrativos na- turais "promovem uma variante de opção turística atraente baseada em fundamentos ecológicos [...]" (Ibidem, p. 35).

O estudo de viabilidade para o desenvolvimento de atividades turísticas no itinerário percorrido, uma vez identificada sua vocação esportiva, deverá estar calcado em outros estudos para prevenção de impactos ambientais e de acidentes, bem como no desenvolvimento de um programa de educação esportiva para os visitantes e também no acompanhamento de profissionais qualificados quando das visitações.

Também não pode-se deixar de ressaltar a necessidade de levantar as medidas a serem empregadas pelo poder público e empreendedores privados para a correta utilização dos atrativos citados no artigo. Sobretudo aquelas de conservação da natureza, dentro da legislação em vigor, para impedir que empreendimentos sejam instalados em desacordo com as leis pertinentes, evitando um turismo feito a qualquer custo.

De acordo com Casasola (1990, p. 14):

Es muy importante [...] definir con claridad los ámbitos de acción y las responsabilidades que cada uno de los sectores: público, privado y social tienen en el problema del deterioro y contaminación de los ecosistemas turísticos. Sólo la coordinación de todos los sectores y una legislación severa permitirán evitar o disminuir esos efectos nocivos. El turismo, por sí mismo, difícilmente pude proponer una respuesta adecuada.

Considera-se que tais estudos façam parte de outra fase da pesquisa não empreendida nesse momento, mas de fundamental importância para a proposição de qualquer tipo de atividade turística na área aqui estudada.

\section{REFERÊNCIAS}

AB'SABER, Aziz Nacib. Os domínios de natureza no Brasil: potencialidades paisagísticas. São Paulo: Ateliê Editorial, 2003. 
ALMEIDA, Cristina Guilherme, MORO, Rosemeri Segecin. Análise da cobertura florestal no Parque Nacional dos Campos Gerais, Paraná, como subsídio ao seu plano de manejo. Terr@ Plural. v. 1, n. 1, p. 115-122, jun. 2007.

BAHL, Miguel. Legados étnicos e oferta turística. Curitiba: Juruá, 2004.

BIGG-WITHER, Thomas Plantagenet. Novo caminho no Brasil meridional: a Província do Paraná. Três anos em suas florestas e campos - 1872/1875. Rio de Janeiro/Curitiba: Livraria José Olympio Editora, 1974.

BRAZ, Fábio Cezar; CALVENTE, Maria del Carmen Huertas. Sociedade e ambiente: um diálogo crítico sobre a Sustentabilidade e o Turismo. In: CARVALHO, Márcia Siqueira de. (Org.). Geografia, meio ambiente e desenvolvimento. Londrina: A autora. p. 165-178, 2003.

CASASOLA, Luis. Turismo y ambiente. México: Trillas, 1990.

FERRETTI, Eliane Regina Turismo e meio ambiente: uma abordagem integrada. São Paulo: Roca, 2002.

LEVI-STRAUSS, Claude. Tristes trópicos. São Paulo: Companhia das Letras, 1996.

IBAMA. Instituto Brasileiro do Meio Ambiente e dos Recursos Naturais Renováveis. Parque Nacional dos Campos Gerais. Disponível em: <http:/ / www.ibama.gov.br/siucweb/listaUcCategoria. php?abrev=PARNA>. Acesso em: 09 jan. 2010.

IBGE. Instituto Brasileiro de Geografia e Estatística. Carta topográfica Quero-Quero. 1:50.000. Folha SG. 22-X-C-III-3. MI 2841-3. 2.ed. 1990.

IGNARRA, Luis Renato. Fundamentos do turismo. São Paulo: Pioneira Thomson Learning, 2001.

KICHE, G. S. et al. Definição das unidades de paisagem com base em um Perfil Geoecológico do Estado do Paraná - Escala 1:750.000. In: SEMINÁRIO LATINOAMERICANO DE GEOGRAFIA FÍSICA, 4, 2006, Maringá. Anais... Maringá: Departamento de Geografia da Universidade Estadual de Maringá, 2006.

LOPES, José Carlos Veiga. Informações sobre os bens de Nossa Senhora das Neves no Paraná. Palmeira: O autor, 2000.

MAACK, Reinhard. Notas preliminares sobre o clima, solos e vegetação do Estado do Paraná. Arquivos de Biologia e Tecnologia, v. 3, art. 12. Curitiba: UFPR, p. 99-200, 1948.
Geografia física do Estado do Paraná. 2 .ed. Rio de Janeiro: Livraria José Olympio Editora, 1981.

MARTINS, Tiago Damas. Superfícies aplainadas na bacia hidrográfica do altíssimo Rio Tibagi. 2008. Dissertação (Mestrado em Geografia) - Programa de Pós-Graduação em Geografia, UFPR, Curitiba - PR.

MONTEIRO, Carlos Augusto de Figueiredo. Geossistemas: a história de uma procura. São Paulo: Contexto, 2000.

NADALIN, Sérgio Odilon. Paraná: ocupação do território, população e migrações. SEED: Curitiba, 2001.

PARANACIDADE. Ortocarta-imagem QueroQuero. MI 2841-3. 1:50.000. 2006.

PELLEGRINI FILHO, Américo. Dicionário enciclopédico de ecologia \& turismo. São Paulo: Manole, 2000.

PIEKARZ, G. F.; LICCARDO, Antonio. Turismo geológico na Rota dos Tropeiros, Paraná. Revista Global Tourism. v. 3, n. 2, 2007. Disponível em: <http:/ / www.periodicodeturismo.com.br>. Acesso em: 06 out. 2009.

SANTOS, Alessandra Santos dos; MOLIN, Elisiane Dondé Dal. Elementos históricos pertencentes ao sistema turístico: avaliação estrutural dos museus localizados na Rota dos Tropeiros - Região dos Campos Gerais (Pr). Revista Turismo \& Sociedade. v. 1, n. 1. Curitiba: UFPR, p. 53-73, 2008.

STIPP, Nilza Aparecida Freres (Org.). Macrozoneamento ambiental da bacia hidrográfica do Rio Tibagi (Pr). Londrina: Eduel, 2000.

UEPG - UNIVERSIDADE ESTADUAL DE PONTA GROSSA. Patrimônio natural dos Campos Gerais do Paraná. Ponta Grossa, 2004. Disponível em:< http://www.uepg.br/natural>. Acesso em: 27 abr. 2009.

ZUCCHERELLI, Moara. A rota dos tropeiros: projeto turístico na região dos Campos Gerais: um olhar antropológico. Dissertação de Mestrado. Programa de Pós-Graduação em Antropologia Social. UFPR, 2008. 111 p.

Recebido em 08/06/10

Aceito para publicação em 21/08/10 